\title{
La violación de derechos humanos en la Ley de Instituciones de Crédito*
}

\section{The violation of human rights in the Law of Credit Institutions}

\author{
Víctor Hugo JimÉnez GonzÁlez**
}

\section{RESUMEN}

En México, el ordenamiento jurídico financiero regulador de las prácticas bancarias, especificamente el artículo 100 de la Ley de Instituciones de Crédito, pareciera quedar fuera del alcance de las normas constitucionales garantes de los derechos humanos de seguridad e igualdad juridica y de acceso a una justicia imparcial en la que se cumplan las formalidades esenciales del procedimiento, toda vez que el artículo al que se hace referencia contempla, en caso de controversia, la posibilidad de que las instituciones bancarias, en beneficio de sus intereses, puedan aportar como medio de prueba impresiones certificadas por funcionario autorizado por ellas mismas, las cuales tendrán en juicio el mismo valor probatorio que libros, registros y documentos microfilmados o grabados en discos ópticos obtenidos de sus originales. Tal disposición sitúa en indefensión legal al cuentahabiente dado que a la institución de crédito le es permisible, de cierta manera, la potencial manufactura de sus medios probatorios.

PALABRAS CLAVE: instituciones de crédito, cuentahabiente, teleológico, convicción, hechos controvertidos.

\begin{abstract}
In Mexico, the financial legal order regulating banking practices, specifically Article 100 of the Law on Credit Institutions, seems to fall outside the scope of constitutional provisions guaranteeing human rights of security, legal equality and access to justice in compliance with the essential procedural requirements; The foregoing is affirmed in as much as the article referred to includes, in the case of a dispute, the possibility that such may provide as proof of evidence, impressions certified by and authorized person that will have the same value as the ones in the books, records and documents microfilmed, even the ones recorded on optical disks obtained from its originals. Such provisions place the account holder in legal helplessness, because the credit institution, in certain way, it's able to "create" its own evidence.
\end{abstract}

Keywords: credit institutions, account holder, teleological, conviction, controversial facts.

* Artículo de investigación recibido el 14 de febrero de 2017 y aceptado para publicación el 18 de septiembre de 2017

** Estudiante del Programa de Doctorado en Derecho de la Benemérita Universidad Autónoma de Puebla, México. (vicblue100@hotmail.com) orcid.org/0000-0003-0895-5795. 
SUMARI0: 1. Introducción/2. Marco legal aplicable/3. Supremacía constitucional (aspectos generales) / 4. Instituciones, servicios y operaciones en la Ley de Instituciones de Crédito y Código de Comercio / 5. Juicio / 6. Conclusiones

\section{INTRODUCCIÓN}

Las actividades donde intervienen e interactúan seres humanos regularmente conllevan la posibilidad de desacuerdos y controversias; en ese sentido, las relaciones comerciales, económicas y financieras pueden verse inmersas en tales polémicas, y para dirimirlas existen conforme a derecho diversos medios de solución.

Uno de esos medios de solución es el proceso, que, definido por José Ovalle Favela, se instituye como la participación en el conflicto de un órgano jurisdiccional del Estado con facultades para no sólo emitir una resolución obligatoria para las partes, sino también para imponerla por sí mismo en forma coactiva, ${ }^{1}$ resultando este el medio más seguro para obtener una solución justa y apegada a derecho.

Así, al contemplarse el proceso como solución a las posibles controversias dentro de las leyes moderadoras de las relaciones financieras, nos encontramos con que éstas son vastas, y si bien pudiese pensarse que tal pluralidad beneficia o puede beneficiar a quien contrate con una institución bancaria, cabe aclarar que procesalmente no son uniformes ni apegadas al principio de igualdad, lo cual crea lagunas legales aprovechadas por los autoritarios sistemas financieros privados, en detrimento de los derechos humanos de los particulares.

La existencia de preceptos como los artículos en estudio de la Ley de Instituciones de Crédito violenta derechos fundamentales, lo cual obliga al Estado, a través de los órganos jurisdiccionales reguladores del proceso, a proteger de manera adecuada a la parte débil en la relación procesal cuya necesidad de protección es mayor, puesto que una de las partes (la institución financiera) se ostenta con una clara posición de superioridad frente a la otra. Para ello, debe atenderse a la supremacía constitucional.

De este modo, al optar por dirimir el conflicto en juicio, la ley prevé que la tramitación del procedimiento mercantil que abarca al financiero, según el caso, se formalizará a través de las siguientes vías de ejercicio:

\footnotetext{
${ }^{1}$ Ovalle Favela, José, Teoría general del proceso, Oxford University Press, México, 2005, p. 29.
} 
a) La vía ordinaria

b) La vía ejecutiva

c) La vía oral mercantil

d) Los de tramitación especial

Corresponde al juez dirigirlo y a las partes aportar las pruebas reconocidas y admitidas por la ley -dado que se trata de derecho privado-, determinándose que la palabra prueba significa ocupar los mecanismos a través de los cuales las partes tratan de acreditar ante el juzgador la veracidad de sus afirmaciones y si ese mecanismo es el adecuado para acreditar la verdad (idoneidad de la prueba). ${ }^{2}$

\section{Marco legal aplicable}

Constitución Política de los Estados Unidos Mexicanos, Código de Comercio y Ley de Instituciones de Crédito publicada en el Diario Oficial de la Federación el 18 de junio de mil novecientos noventa. ${ }^{3}$

\section{Supremacía constitucional (aspectos generales)}

En México, el ordenamiento jurídico se basa en la Constitución, conforme a su artículo 133, que establece lo que se conoce como supremacía constitucional:

Artículo 133. Esta Constitución, las Leyes del Congreso de la Unión que emanen de ella y todos los Tratados que estén de acuerdo con la misma, celebrados y que se celebren por el Presidente de la República, aprobados por el Senado, serán la Ley Suprema de toda la Unión. Los jueces de cada Estado se arreglaran a dicha Constitución, Leyes y Tratados, a pesar de las disposiciones en contrario que pueda haber en las Constituciones o leyes de los Estados.

De conformidad con ello, los artículos 14 y 17 constitucionales establecen que nadie podrá ser privado de la libertad o de sus propiedades, posesiones o derechos, sino mediante juicio seguido ante los tribunales previamente esta-

\footnotetext{
${ }^{2}$ Contreras Vaca, Francisco José, Derecho procesal mercantil, teoría y clínica, México, Oxford University Press, 2011, p. 137. ${ }^{3}$ Ley de instituciones de Crédito, Diario Oficial de la Federación, México, 1990. Disponible en: http://www.ordenjuridico.gob.mx/Publicaciones/CDLeyesyReg05/pdf/L-36.pdf.
} 
blecidos, en el que se cumplan las formalidades esenciales del procedimiento y conforme a las leyes expedidas con anterioridad al hecho, además de que toda persona tiene derecho a que se le administre justicia por tribunales que estarán expeditos para impartirla en los plazos y términos que fijen las leyes, emitiendo sus resoluciones de manera pronta, completa e imparcial. Su servicio será gratuito, por lo que como consecuencia quedarán prohibidas las costas judiciales.

Se establece entonces que todo procedimiento judicial deberá cumplirse con formalidades esenciales y que la justicia que se imparta debe ser imparcial, es decir, es un deber del Estado dar un trato igual a las partes que intervienen en un juicio, las mismas oportunidades en igualdad de circunstancias de probar su dicho y hacer exigibles las obligaciones a las que se hayan sometido.

Sin embargo, las aplicaciones de tales preceptos constitucionales son frecuentemente irrealizables debido a la complejidad de las normas ordinarias que comprometen los derechos considerados como fundamentales y contrarían los mandatos constitucionales.

Resulta aquí conveniente citar algunas opiniones de autores que nos permitirán inferir el carácter teleológico de la Constitución. Para Ignacio Burgoa, la Constitución debe ser considerada como lex fundamental o primaria, como ordenamiento básico de toda estructura jurídica estatal y cimiento sobre el que se asienta el sistema normativo del derecho en su integridad. ${ }^{4}$ Maurice Duverger afirma que la supremacía de la Constitución significa que las leyes deben estar de acuerdo con la Carta Máxima, de lo contrario serían irregulares y no tendrían aplicación. ${ }^{5}$ Nogueira Alcalá menciona que los fines establecidos en la carta fundamental constituyen una garantía institucional a la protección del contenido esencial de los derechos con fuerza vinculante erga omnes, considerando que muchas de las amenazas a los derechos humanos no sólo provienen del Estado, sino también y principalmente de los poderes económicos y sociales facticos de la propia sociedad civil. ${ }^{6}$ Víctor M. Castrillón y Luna sugiere que la Constitución erige un orden jurídico superior que fundamenta a todo el sistema tanto de derecho como institucional por contener los principios fundamentales de la soberanía nacional; por tanto, la

\footnotetext{
${ }^{4}$ Burgoa Orihuela, Ignacio, Derecho Constitucional Mexicano, 3a. Ed., México, Porrúa, 1979, Págs. 327 y 328.

${ }^{5}$ Citado por Castrillón y Luna, Victor Manuel, "La protección constitucional de los derechos humanos", Instituciones politicas y derecho constitucional, Barcelona, Ariel, 1968, p. 242.

${ }^{6}$ Nogueira Alcalá, Humberto, Teoría y dogmática de los derechos fundamentales, Instituto de Investigaciones Juridicas-UNAM, México, 2003, p. 78.
} 
superioridad de la Carta Magna implica que no se puede tolerar la existencia de leyes o actos contrarios a su objetivo. ${ }^{7}$

Estos discernimientos claramente indican de manera generalizada que las normas de todo ordenamiento jurídico deben ser interpretadas en armonía con su Constitución, respetando en todo momento los derechos humanos consagrados en su texto.

En consecuencia y como tema central, analizaremos las paradojas observadas en la Ley de Instituciones de Crédito, en sus artículos 99 y 100, que se vuelven conniventes a los intereses de las instituciones de banca, concibiendo "al cliente" como toda persona que decide abrir una cuenta en una institución de crédito y depositar en ella parte o la totalidad de su capital. Para ello, resulta necesario determinar el concepto de comerciante, acto de comercio y obligaciones de los comerciantes dentro de la Ley Comercial en México.

\section{INSTITUCIONES, SERVICIOS Y OPERACIONES EN LA LEY DE INSTITUCIONES de Crédito y Código de Comercio}

El acto de voluntad supone la reunión de dos elementos: el consentimiento y la consideración del fin a conseguir. El acto de voluntad, cuando se vierte en el molde de un contrato cualquiera, se haya vinculado a la realización de un fin, a la obtención de un resultado jurídico. ${ }^{8} \mathrm{Al}$ efecto, si un particular realiza un acto jurídico (contrato) con una institución de crédito; de manera sinalagmática se crean derechos y obligaciones. Al particular se le considerará como cliente o cuentahabiente, y la institución de crédito tiene como finalidad la captación de recursos del público en el mercado nacional, para su colocación mediante actos causantes de pasivo directo o contingente, quedando el intermediario obligado a cubrir el principal y, en su caso, los accesorios financieros de los recursos captados. ${ }^{9}$

Las instituciones de crédito podrán ser de banca múltiple o banca de desarrollo, y las operaciones a las que refiere este estudio son las que se encuentran contempladas en la fracción I del artículo 46 de la Ley de Instituciones de Crédito:

\footnotetext{
${ }^{7}$ Castrillón y Luna, Victor Manuel, La protección constitucional de los derechos humanos, México, Porrúa, 2006, p. 34.

${ }^{8}$ Lutzesco, Georges, Teoría y Práctica de las Nulidades, 12a Edición, México, Porrúa, 2010, P. 197.

${ }^{9}$ Artículo $2^{\circ}$, Ley de Instituciones de Crédito, Diario Oficial de la Federación, México, 1990, http://www.diputados. gob.mx/LeyesBiblio/pdf/43_170616.pdf.
} 
Artículo 46.- Las instituciones de crédito sólo podrán realizar las operaciones siguientes:

I. Recibir depósitos bancarios de dinero:

a) A la vista

b) Retirables en días preestablecidos

c) De ahorro

d) A plazo o con previo aviso ${ }^{10}$

La personalidad jurídica, los derechos y obligaciones creados a los que se constriñe la institución de crédito como parte en el acto jurídico en que intervenga es un acto netamente mercantil regulado por el Código de Comercio; tal regulación la encontraremos en sus artículos 3 y 16, en específico en las fracciones II y III respectivamente, así como en los numerales 33, 49 y 75 (se transcriben):

Artículo 3o.- Se reputan en derecho comerciantes:

I.- $\quad$ Las personas que teniendo capacidad legal para ejercer el comercio, hacen de él su ocupación ordinaria;

II.- Las sociedades constituidas con arreglo a las leyes mercantiles;

III.- Las sociedades extranjeras o las agencias y sucursales de éstas, que dentro del territorio nacional ejerzan actos de comercio.

Artículo 16.- Todos los comerciantes, por el hecho de serlo, están obligados.

I. (Se deroga).

II.- A la inscripción en el Registro público de comercio, de los documentos cuyo tenor y autenticidad deben hacerse notorios;

III.- A mantener un sistema de Contabilidad conforme al artículo 33.

De la Contabilidad Mercantil

Artículo 33.- El comerciante está obligado a llevar y mantener un sistema de contabilidad adecuado. Este sistema podrá llevarse mediante los instrumentos, recursos y sistemas de registro y procesamiento que mejor

\footnotetext{
${ }^{10}$ Artículo 10 , Ley de Instituciones de Crédito, Diario Oficial de la Federación, México, 1990, http://www.diputados. gob.mx/LeyesBiblio/pdf/43_170616.pdf.
} 
se acomoden a las características particulares del negocio, pero en todo caso deberá satisfacer los siguientes requisitos mínimos:

A) Permitirá identificar las operaciones individuales y sus características, así como conectar dichas operaciones individuales con los documentos comprobatorios originales de las mismas.

B) Permitirá seguir la huella desde las operaciones individuales a las acumulaciones que den como resultado las cifras finales de las cuentas y viceversa;

C) Permitirá la preparación de los estados que se incluyan en la información financiera del negocio;

D) Permitirá conectar y seguir la huella entre las cifras de dichos estados, las acumulaciones de las cuentas y las operaciones individuales;

E) Incluirá los sistemas de control y verificación internos necesarios para impedir la omisión del registro de operaciones, para asegurar la corrección del registro contable y para asegurar la corrección de las cifras resultantes.

Artículo 49.- Los comerciantes están obligados a conservar por un plazo mínimo de diez años los originales de aquellas cartas, telegramas, mensajes de datos o cualesquiera otros documentos en que se consignen contratos, convenios o compromisos que den nacimiento a derechos y obligaciones.

Para efectos de la conservación o presentación de originales, en el caso de mensajes de datos, se requerirá que la información se haya mantenido integra e inalterada a partir del momento en que se generó por primera vez en su forma definitiva y sea accesible para su ulterior consulta.

La Secretaría de Economía emitirá la Norma Oficial Mexicana que establezca los requisitos que deberán observarse para la conservación de mensajes de datos.

Artículo 75.- La ley reputa actos de comercio:

I...

II...

III...

XIV.- Las operaciones de bancos. 
De tal contexto legal, ciertamente cabe acotar que para las instituciones de crédito la obligación de conservar en papel cualesquiera otros documentos en que se consignen contratos, convenios o compromisos que den nacimiento a derechos y obligaciones por un lapso no menor a diez años acarrearía una afectación a su competitividad y eficacia, además de los problemas de altos costos para su debida conservación, certidumbre y localización inmediata; por consiguiente, se publica el 18 de julio de 1990 la Ley de Instituciones de Crédito, que, conjuntamente con las reformas al Código de Comercio publicadas en el Diario Oficial de la Federación (DOF) el 29 de agosto de 2003, ${ }^{11}$ determinarán la personalidad jurídica, la capacidad legal, los derechos y obligaciones de las instituciones de crédito, así como también la posibilidad de "microfilmar o grabar en discos ópticos, o en cualquier otro medio que les autorice la Comisión Nacional Bancaria y de Valores, todos aquellos libros, registros y documentos en general, que obren en su poder, relacionados con los actos de la propia institución, que mediante disposiciones de carácter general señale la Comisión Nacional Bancaria y de Valores, de acuerdo a las bases técnicas que para la microfilmación o la grabación en discos ópticos, su manejo y conservación establezca la misma" (se transcriben):

Artículo 10.- La presente Ley es de orden público y observancia general en los Estados Unidos Mexicanos y tiene por objeto regular el servicio de banca y crédito, la organización y funcionamiento de las instituciones de crédito, las actividades y operaciones que las mismas podrán realizar, su sano y equilibrado desarrollo, la protección de los intereses del público y los términos en que el Estado ejercerá la rectoría financiera del Sistema Bancario Mexicano.

Artículo reformado DOF 01-02-2008

Artículo 2o.- El servicio de banca y crédito sólo podrá prestarse por instituciones de crédito, que podrán ser:

I. Instituciones de banca múltiple, y

II. Instituciones de banca de desarrollo.

\footnotetext{
"Código de Comercio, Diario Oficial de la Federación, México, 2003. Disponible en: http://www.diputados.gob.mx/ LeyesBiblio/ref/ccom/CCom_ref29_29ago03.pdf.
} 
Artículo 6o.- En lo no previsto por la presente Ley y por la Ley Orgánica del Banco de México, a las instituciones de banca múltiple se les aplicarán en el orden siguiente:

- La legislación mercantil;

- Los usos y prácticas bancarios y mercantiles, y

- La legislación civil federal. Fracción reformada D0F 06-02-2008

- La Ley Federal de Procedimiento Administrativo respecto de la tramitación de los recursos a que se refiere esta Ley, y

- El Código Fiscal de la Federación respecto de la actualización de multas.

- Las instituciones de banca de desarrollo, se regirán por su respectiva ley orgánica y, en su defecto, por lo dispuesto en este artículo.

Artículo 99.- Todo acto o contrato que signifique variación en el activo o en el pasivo de una institución de crédito o implique obligación directa o contingente, deberá ser registrado en la contabilidad el mismo día en que se efectúen. La contabilidad, los libros y documentos correspondientes y el plazo que deban ser conservados, se regirán por las disposiciones de carácter general que dicte la Comisión Nacional Bancaria y de Valores tendientes a asegurar la confiabilidad, oportunidad y transparencia de la información contable y financiera de las instituciones. Artículo reformado DOF 01-02-2008.

La contabilidad con los ajustes requeridos por la Comisión Nacional Bancaria y de Valores será la utilizada para todos los efectos contables y legales conducentes ${ }^{12}$. Párrafo adicionado DOF 10-01-2014.

Artículo 100.- Las instituciones de crédito podrán microfilmar o grabar en discos ópticos, o en cualquier otro medio que les autorice la Comisión Nacional Bancaria y de Valores, todos aquellos libros, registros y documentos en general, que obren en su poder, relacionados con los actos de la propia institución, que mediante disposiciones de carácter general señale la Comisión Nacional Bancaria y de Valores, de acuerdo a las bases técnicas que para la microfilmación o la grabación en discos ópticos, su manejo y conservación establezca la misma. Los negativos originales de cámara obtenidos por el sistema de microfilmación y las imágenes

${ }^{12}$ Artículo 99, Ley de Instituciones de Crédito, Diario Oficial de la Federación, México, reforma 2014. Disponible en: http://www.diputados.gob.mx/LeyesBiblio/pdf/43_170616.pdf. 
grabadas por el sistema de discos ópticos o cualquier otro medio autorizado por la Comisión Nacional Bancaria y de Valores, a que se refiere el párrafo anterior, así como las impresiones obtenidas de dichos sistemas o medios, debidamente certificadas por el funcionario autorizado de la institución de crédito, tendrán en juicio el mismo valor probatorio que los libros, registros y documentos microfilmados o grabados en discos ópticos, o conservados a través de cualquier otro medio autorizado ${ }^{13}$. Artículo reformado DOF 30-04-1996.

Sin embargo, su incorrecta exégesis acarrea como resultado que en la práctica se conciba una consunción de la hegemonía constitucional, posibilitando que las actuaciones de las instituciones de crédito amenacen y lesionen derechos fundamentales dentro de sus relaciones contractuales.

\section{Ju1c10}

Pensemos ahora en esos documentos en que se consignen contratos, convenios o compromisos que dan nacimiento a derechos y obligaciones entre las instituciones de crédito y sus clientes, y que estos documentos se aporten como medios de prueba en un procedimiento judicial con cánones tan disímiles como los transcritos. ¿Será posible una verdadera imparcialidad en la aplicación de justicia? ¿El desarrollo económico equitativo y sustentable de nuestro país es responsabilidad del Poder Ejecutivo y del Poder Legislativo únicamente? La respuesta a estas interrogantes la encontramos en la necesaria intervención del Poder Judicial como tutor de la ejecución de los derechos fundamentales. Tal como lo apunta Luis Prieto Sanchís, la garantía de la Constitución se atribuye al más "neutro" de los poderes, a aquel que debe y que mejor pueda mantenerse al margen del debate político, es decir, al Poder Judicial. ${ }^{14}$

Al efecto, comencemos por mencionar que el juicio se tramitará por las vías de ejercicio ordinario u oral mercantil dependiendo del monto de la obligación y porque la fuente de tales derechos y obligaciones es un contrato; pese a lo anterior, es pertinente señalar que, por tratarse de una controversia

\footnotetext{
${ }^{13}$ Artículo 100, Ley de Instituciones de Crédito, Diario Oficial de la Federación, México, reforma 2014. Disponible en: http://www.diputados.gob.mx/LeyesBiblio/pdf/43_170616.pdf.

${ }^{14}$ Citado por Résendez Bocanegra, Pedro Javier, Protección del Derecho a Decidir y Contratar Libremente: su Impacto en la Sociedad, Prieto Sanchis, Luis, "Neoconstitucionalismo y Ponderación Judicial", P. 66.
} 
de índole mercantil y al estar regulada por leyes federales, el actor puede hacer uso de la jurisdicción concurrente, esto es, puede optar por ventilar la controversia ante los tribunales de la federación o en los tribunales del orden común, siempre y cuando sólo se afecten intereses particulares, tal como lo establece el artículo 104 de la Constitución Política de los Estados Unidos Mexicanos:

Luego, al presentarse la demanda y cumplir con los presupuestos procesales, el tribunal declarará su competencia y quedará obligado constitucionalmente a garantizar una aplicación de justicia imparcial, además de cumplir con las formalidades del procedimiento y con cada una de sus etapas.

De manera particular, en la etapa expositiva las partes deberán cumplir, dentro de otras obligaciones, el mencionar el valor de lo demandado, pues de ello dependen la competencia del juez y los documentos en que la parte interesada funde su derecho, ${ }^{15}$ es decir, ofrecerán sus pruebas, las cuales deberán cumplir con lo que establece el artículo 1205 del Código de Comercio:

Artículo 1205.- Son admisibles como medios de prueba todos aquellos elementos que puedan producir convicción en el ánimo del juzgador acerca de los hechos controvertidos o dudosos y en consecuencia serán tomadas como pruebas las declaraciones de las partes, terceros, peritos, documentos públicos o privados, inspección judicial, fotografías, facsímiles, cintas cinematográficas, de videos, de sonido, mensajes de datos, reconstrucciones de hechos y en general cualquier otra similar u objeto que sirva para averiguar la verdad.

Igual regla se debe seguir en caso de que se trate de juicio oral mercantil, tal como se contempla en el artículo 1390 Bis 11, fracciones V y VIII:

Juicio Oral Mercantil

Fijación de la Litis

Artículo 1390 Bis 11.- La demanda deberá presentarse por escrito y reunirá los requisitos siguientes:

I. El juez ante el que se promueve;

${ }^{15}$ Contreras Vaca, Francisco José, Derecho Procesal Mercantil, Teoria y Clínica, 2a. Ed., México, Oxford, 2011 Págs. 96 y 97. 
II. El nombre y apellidos, denominación o razón social del actor y el domicilio que señale para oír y recibir notificaciones;

III. El nombre y apellidos, denominación o razón social del demandado y su domicilio;

IV. El objeto u objetos que se reclamen con sus accesorios;

V. Los hechos en que el actor funde su petición en los cuales precisará los documentos públicos o privados que tengan relación con cada hecho, así como si los tiene a su disposición. De igual manera proporcionará los nombres y apellidos de los testigos que hayan presenciado los hechos relativos.

Asimismo, debe numerar y narrar los hechos, exponiéndolos sucintamente con claridad y precisión;

VI. Los fundamentos de derecho y la clase de acción procurando citar los preceptos legales o principios jurídicos aplicables;

VII. El valor de lo demandado;

VIII. El ofrecimiento de las pruebas que el actor pretenda rendir en el juicio, y

IX. La firma del actor o de su representante legítimo. Si éstos no supieren o no pudieren firmar, pondrán su huella digital, firmando otra persona en su nombre y a su ruego, indicando estas circunstancias.

Posteriormente, una vez entablada la Litis, se pasará a la etapa probatoria, considerada como fase del proceso dentro de la cual las partes tienen la oportunidad de acreditar su dicho ante el juez, correspondiéndole al actor hacerlo respecto a los hechos constitutivos de su acción y al demandado, en relación con sus defensas y excepciones; etapa donde por supuesto deben tenerse presentes los cinco principios básicos de la actividad probatoria ${ }^{16}$ para su admisión:

Fin. Para que el juzgador se allegue de los elementos necesarios para analizar debidamente la veracidad de las afirmaciones de las partes y estar en aptitud de dictar una sentencia.

Necesidad. Para delimitar cuáles son las cuestiones planteadas dentro del proceso que tienen que ser probadas.

\footnotetext{
${ }^{16}$ Contreras Vaca, Francisco José, op. cit., p. 138.
} 
Carga. Para determinar a qué parte le corresponde y respecto a qué hechos debe aportar instrumentos probatorios para acreditar su veracidad.

Idoneidad. Para determinar cuál es el medio de prueba adecuado.

Sujetos. Para señalar quiénes son las personas que han de intervenir en el desahogo de los instrumentos probatorios.

Es en el periodo de la admisión de pruebas propuestas por las partes donde cobra vida el contrasentido sujeto a estudio, pues si resulta ser que la institución bancaria microfilmó o grabó en discos ópticos o en cualquier otro medio que autorice la Comisión Nacional Bancaria y de Valores, los documentos que obren en su poder, relacionados con el juicio, y que correspondan a la propia institución los podrá imprimir y certificar por medio de funcionario autorizado de la institución de crédito, y dichos documentos tendrán en juicio el mismo valor probatorio que los libros, registros y documentos microfilmados o grabados en discos ópticos, o conservados a través de cualquier otro medio autorizado, pero sin que en ningún momento estén obligados a garantizar la certeza de dichas impresiones, dado que han sido "certificadas por el funcionario autorizado de la institución de crédito”, presumiéndose entonces que los datos que provienen de las instituciones de crédito corresponden íntegramente a las constancias que en ellos figuran y a la realidad, generándose con ello una presunción de certeza suficiente para darle pleno valor probatorio en juicio y obligar a la contraparte (cuentahabiente), si le resulta necesario, no sólo a objetar las impresiones presentadas, sino también a la inalcanzable obtención de otros medios de prueba que logren destruir la presunción de certeza de la información aportada por la institución de crédito.

Así, al tomar en consideración los artículos puntualizados, es manifiesto que quien gozará de una preeminencia al momento de probar su dicho será la institución de crédito, dado que no se garantiza el uso de prácticas bancarias sanas y mucho menos propician la seguridad de esas operaciones. Esto contraria el crecimiento de la economía nacional pues no existe una verdadera protección a la inversión. En consecuencia, la repercusión social de un patrón de conducta como el señalado deja de ser un asunto privado y pasa a ser un asunto de relevancia pública, donde los órganos judiciales asuman la posición de defender la eficacia de los derechos fundamentales y no dejen esa carga procesal a los particulares. 


\section{Conclusiones}

El objetivo de este análisis es enfatizar los riesgos que se corren con leyes que contrarían a la Constitución y tienden a la desprotección de los derechos fundamentales; así también, se propone que las normas procesales, tanto federales como estatales, sean interpretadas según los principios que establece la propia Constitución, uniendo nuestra voz (respetando, claro está, las debidas proporciones) a la de destacados juristas cuya propuesta es que toda norma atienda y custodie los derechos fundamentales.

La impartición de justicia, con posibilidad de particularizarla a grado tal de darle valor probatorio a un documento presentado y certificado por una de las partes, sitúa en un escenario considerablemente desfavorable a quien se atreve a llevar ante los tribunales a una institución bancaria, ya que al hacerlo corre grave riesgo de no poder demostrar sus aseveraciones y, peor aún, de no tener garantía constitucional que le proteja en caso de violaciones al procedimiento.

Por tanto, reflexionar y reconocer la existencia de disposiciones legales que nos obligan a conducirnos dentro de una secuela procesal de forma determinada hacen necesaria la intervención positiva del Estado para garantizar la salvaguarda de los derechos humanos, para evitar, entre otras cosas, la consecuencia de concentrar la riqueza en un sector beneficiado de la población.

Bien menciona Luigi Ferrajoli tales consecuencias, a las que considera "la crisis del estado nacional", y las interpreta como la crisis de la misma capacidad regulativa del derecho debido, entre otras cosas, a la pluralidad de las fuentes normativas, a su subordinación a imperativos sistémicos de tipo económico y, por otra parte, a una creciente incoherencia, falta de plenitud, imposibilidad de conocimiento e ineficacia del sistema jurídico, que acarreara como consecuencia el debilitamiento del constitucionalismo y, por tanto, de garantía de los derechos fundamentales. ${ }^{17}$

En efecto, la variación significativa que puede darse en la resolución de un procedimiento judicial al permitir a una de las partes certificar sus propias pruebas y con ello darle valor probatorio pleno legitima un retroceso legal y obliga a realizar una profunda exploración y, como consecuencia, una necesaria reforma al artículo 100 de la Ley de Instituciones de Crédito, para precisar la autenticidad de las impresiones certificadas que pueden aportarse

\footnotetext{
${ }^{17}$ Ferrajoli, Luigi, Derechos y Garantías, la Ley del más Débil, 7ª. Ed., Trotta, 2010, P. 17.
} 
en un procedimiento jurisdiccional; es decir, que la misma ley provea el mecanismo en que la parte contraria a la institución de crédito pueda exigir el comprobar la autenticidad de los elementos de prueba.

Una viable solución concurrirá sí la protección constitucional a los derechos fundamentales y la propia validez de la Constitución hacen replica en las leyes y códigos tanto federales como estatales; como ejemplo, el artículo 13, fracción V, del Código de Procedimientos Civiles para el Estado de Tabasco, que indica:

En la interpretación de las normas procesales tendrán aplicación las siguientes reglas:

V. Las normas procesales deberán interpretarse de conformidad con los principios que establece la Constitución Política de los Estados Unidos Mexicanos sobre el proceso y la función jurisdiccional, con los principios generales del derecho y con los principios fundamentales contenidos en este Código, de manera que se observen, en todo caso, las formalidades de un proceso justo y razonable. ${ }^{18}$

Esto, bajo la condición de que todo orden jurídico será eficaz si y sólo si armoniza con su norma fundamental (la Constitución) lo que conllevará por lógica a su validez. Como señala García de Enterría, la Constitución asegura una unidad del ordenamiento jurídico, esencialmente sobre la base de un orden de valores materiales expresados en ella y no sobre las simples reglas formales de producción de las normas ${ }^{19}$. De ahí que "sólo se asume una norma fundamental, cuando estamos en presencia de un orden jurídico eficaz”, es decir, únicamente cuando se satisface la condición suficiente. ${ }^{20}$ En esa postura, como bien apunta Reséndez Bocanegra, el precepto constitucional claramente obliga a los jueces, de cualquier instancia y rango, a aplicar en primer lugar la Constitución y, por ende, también a atender y custodiar los derechos fundamentales. Esto aplica en juicios de todo tipo, incluyendo aquellos que tienen por objeto resolver controversias entre particulares, es decir, también

\footnotetext{
${ }_{18}$ Artículo 13, fracción V, Código de Procedimientos Civiles para el Estado de Tabasco, México, 1997. Disponible en: http://www.eumed.net/librosgratis/2008c/427/Tabasco.\%20Codigo\%20de\%20Procedimientos\%20Civiles.pdf.

${ }^{19}$ Garcia de Enterria, Eduardo, La constitución como norma y el tribunal constitucional, Madrid, España, Civitas, 2006, p. 97.

${ }^{20}$ Tamayo y Salmorán, Rolando, Costumbre o eficacia, condición necesaria y suficiente de existencia del derecho, México, Fontamara, 2015, p. 106.
} 
en los juicios en los que se ventilan disputas de orden civil y mercantil, los jueces están obligados a aplicar, en primer lugar, los preceptos constitucionales y tutelar los derechos fundamentales. ${ }^{21}$

\section{RefERENCIAS}

Burgoa Orihuela, Ignacio, Derecho constitucional mexicano, México, Porrúa, 1979, pp. 327-328.

Castrillón y Luna, Víctor Manuel, "La protección constitucional de los derechos humanos”, Instituciones politicas y derecho constitucional, Barcelona, Ariel, 1968, p. 242.

Código de Comercio, Diario Oficial de la Federación, México, 2003. Disponible en: http://www.diputados.gob.mx/LeyesBiblio/ref/ccom/CCom_ ref29_29ago03.pdf.

Código de Procedimientos Civiles para el Estado de Tabasco, México, 1997. Disponible en: http://www.eumed.net/librosgratis/2008c/427/Tabasco.\%20Codigo\%20de\%20Procedimientos\%20Civiles.pdf.

Contreras Vaca, Francisco José. Derecho procesal mercantil, teoría y clinica, México, Oxford University Press, 2011, p. 137.

Ferrajoli, Luigi, Derechos y garantías, la ley del más débil, Trotta, Madrid, 2010, p. 17.

García de Enterría, Eduardo, La constitución como norma y el tribunal constitucional, Civitas, Madrid, España, 2006, p. 97.

Ley de instituciones de Crédito, Diario Oficial de la Federación, México, 1990. Disponible en: http://www.ordenjuridico.gob.mx/Publicaciones/CDLeyesyReg05/pdf/L-36.pdf.

Lutzesco, Georges, Teoria y práctica de las nulidades, 12a edición, México, Porrúa, 2010, p. 197.

Nogueira Alcalá, Humberto, Teoría y dogmática de los derechos fundamentales, Instituto de Investigaciones Jurídicas-UNAM, México, 2003, p. 78.

Ovalle Favela, José, Teoría general del proceso, 6ta edición, México, Oxford University Press, 2005, p. 29.

Reséndez Bocanegra, Pedro Javier, Protección del derecho a decidir y contratar libremente, México, Instituto de Investigaciones Jurídicas-UNAM, 2014, p. 124.

Tamayo y Salmorán, Rolando, Costumbre o eficacia, condición necesaria y suficiente de existencia del derecho, México, Fontamara, 2015, p. 106.

\footnotetext{
${ }^{21}$ Reséndez Bocanegra, Pedro Javier, Protección del derecho a decidir y contratar libremente, México, Instituto de Investigaciones Jurídicas-UNAM, 2014, p. 124.
} 